\title{
TOPIC: ABDOMINAL WALL AND INGUINO FEMORAL HERNIA REPAIR AS A SUPER SPECIALIZATION
}

\author{
VS:01 \\ SINGLE-INCISION LAPAROSCOPIC INTRAPERI- \\ TONEAL ONLAY MESH REPAIR OF RECURRENT \\ INGUINAL HERNIA AFTER FAILED ANTERIOR \\ AND LAPAROSCOPIC REPAIR

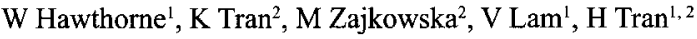 \\ 'University of Sydney at Westmead Hospital, Westmead, AUSTRALIA \\ ${ }^{2}$ Sydney Hernia Specialists Clinic, Sydney, AUSTRALIA
}

Introduction: Despite exponential rise in laparoscopic surgery for inguinal herniorraphy, overall recurrence rates have remained unchanged. Therefore, an increasing number of patients present with recurrent hernias after having failed anterior and laparoscopic repair. This study reports our experience with single-incision laparoscopic (SIL) intraperitoneal onlay mesh (IPOM) repair for these hernias.

Methods: Patients referred with re-recurrent inguinal hernias underwent SIL-IPOM from November 2009-June 2014. A $2.5 \mathrm{~cm}$ infra-umbilical incision was made and a SILS ${ }^{\mathrm{TM}}$ port was placed intraperitoneally via anterior and posterior rectus sheaths. Modified dissection techniques ("chopsticks" and "inline" dissection), $5.5 \mathrm{~mm} / 52 \mathrm{~cm} / 30^{\circ}$ laparoscope and conventional straight dissecting instruments were used. The peritoneum was incised above pubic symphysis and dissection continued laterally and proximally raising inferior flap, below previous extraperitoneal mesh, while reducing any direct/indirect/femoral/cord lipoma before placement of anti-adhesive mesh. This was fixed inferiorly into pubic ramus and superiorly with non-absorbable tacks before fixing its inferior border with fibrin sealant. The inferior peritoneal flap was then tacked back onto mesh.

Results: There were 9 male patients who underwent SIL-IPOM. Mean age was 53 years and mean body mass index was $26.8 \mathrm{Kg} / \mathrm{m}^{2}$. Mean mesh size was $275 \mathrm{~cm}^{2}$. Mean operation time was $125 \mathrm{~min}$ with hospital stay of 1 day and umbilical scar length of $23 \mathrm{~mm}$ at 6 weeks follow-up. There were no intra-/postoperative complications, port-site hernias, chronic groin pain or recurrence with mean follow-up of 24 months.

Conclusion: Recurrent inguinal hernias after failed conventional anterior and laparoscopic repairs can be safely and effectively treated with SIL-IPOM.

\author{
VS:02 \\ SINGLE-INCISION LAPAROSCOPIC INGUINAL \\ HERNIA REPAIR WITH TELESCOPIC EXTRA- \\ PERITONEAL DISSECTION: HOW TO DO IT \\ W Hawthorne ${ }^{1}, \mathrm{~K}$ Tran $^{2}$, M Zajkowska ${ }^{2}$, V Lam ${ }^{1}$, H Tran ${ }^{1,2}$ \\ ${ }^{\prime}$ University of Sydney at Westmead Hospital, Westmead, AUSTRALIA \\ ${ }^{2}$ Sydney Hernia Specialists Clinic, Sydney, AUSTRALIA
}

Introduction: Our recent prospective randomized controlled trial (NCT01660048) comparing single-incision laparoscopic (SIL) totally extraperitoneal (TEP) and multi-incision inguinal herniorraphy confirmed safety, efficacy and benefits of single-incision approach. This study (NCT01883115) aimed to assess safety, efficacy and cost effectiveness of telescopic extraperitoneal dissection.

Methods: Patients with inguinal/femoral hernias from February 2013-February 2014 undergoing SILTEP herniorraphy with telescopic dissection were compared with patients who had previously undergone SILTEP herniorraphy with balloon dissection. Costs of different ports/ trocars were analyzed

Results: There were 102 patients in telescopic compared to 51 in balloon dissection group; these had no significant differences in age, sex, body mass index, American Society of Anesthesiologists and pre-op visual analogue scores. Telescopic vs balloon showed: post-operative pain: day one 2.5 vs $2.5 ; \mathrm{p}=0.90$, day seven 0 vs $0 ; \mathrm{p}=0.02$ ( 0 vs $1 ; p<0.01$ for bilateral hernias), operation times: unilateral $48.0 \mathrm{vs}$ $48.0 \mathrm{~min} ; \mathrm{p}=0.88$ and bilateral 70.0 vs $65.0 \mathrm{~min} ; \mathrm{p}=0.66$, length of hospital stay 1.0 vs 1.0 day, analgesic intake (Dextropropoxyphene) 6.0 vs 6.0 tablets; $p=0.95$, return to work/normal physical activities 7.0 vs 7.0 days; $P=0.46$ and cosmetic scar scores 24.0 vs 24.0 respectively. There was no conversion to open surgery/need for additional ports in either group. Median scar length for telescopic group was $13.0 \mathrm{~mm}$. Costs of disposable ports/trocars for telescopic and balloon groups were US $\$ 480$ and $\$ 720$ respectively. There were no morbidities/recurrences with follow-up of 6-36 months.

Conclusions: Telescopic extraperitoneal dissection during SILTEP inguinal herniorraphy represents a safe and efficient alternative with potential cost savings compared to balloon dissection. 